Article

\title{
The Influence of Process Parameters on the Surface Roughness of a 3D-Printed Co-Cr Dental Alloy Produced via Selective Laser Melting
}

\author{
Min-Ho Hong ${ }^{1}$, Bong Ki Min ${ }^{2}$ and Tae-Yub Kwon ${ }^{3, *}$ \\ 1 Institute for Biomaterials Research \& Development, Kyungpook National University, 2-188-1 Samduk-dong, \\ Jung-gu, Daegu 700-412, Korea; mhhong@knu.ac.kr \\ 2 Center for Research Facilities, Yeungnam University, 214-1 Dae-dong, Gyeongsan 712-749, Korea; \\ bkmin@ynu.ac.kr \\ 3 Department of Dental Biomaterials, School of Dentistry, Kyungpook National University, \\ 2-188-1 Samduk-dong, Jung-gu, Daegu 700-412, Korea \\ * Correspondence: tykwon@knu.ac.kr; Tel.: +82-53-660-6891
}

Academic Editor: Peter Van Puyvelde

Received: 7 November 2016; Accepted: 28 November 2016; Published: 1 December 2016

\begin{abstract}
Selective laser melting (SLM), used to fabricate metallic objects with high geometrical complexity, is currently of increasing interest to the fields of medicine and dentistry. SLM-fabricated products should have highly smooth surfaces to minimize the use of post-processing procedures such as finishing and polishing. This study investigated the effect of various laser process parameters (laser power, scan rate, and scan-line spacing) on the surface roughness of a $\mathrm{Co}-\mathrm{Cr}$ dental alloy that was three-dimensionally (3D) constructed via SLM. Initially, a single-line formation test was used to determine the optimal laser power $(200 \mathrm{~W})$ and scan rate $(128.6 \mathrm{~mm} / \mathrm{s})$ that resulted in beads with an optimal profile. During subsequent multi-layer formation tests, the 3D Co-Cr body with the smoothest surface was produced using a scan-line spacing of $100 \mu \mathrm{m}$. The findings of this study show that laser process parameters have crucial effects on the surface quality of SLM-fabricated Co-Cr dental alloys.
\end{abstract}

Keywords: Co-Cr alloy; powder metallurgy; selective laser melting; surface roughness

\section{Introduction}

Selective laser sintering (SLS), a rapid prototyping and manufacturing technology, was developed in the late 1980s and has been widely employed to produce products from almost any type of material [1]. However, a different power binding mechanism from that of the SLS is necessary to fabricate objects with high density [1,2]. Selective laser melting (SLM) can be used to produce products with near full density, preferably with minimal or no post-processing requirements [1]. The SLM technique is currently widely applied for the fabrication of various high-quality metallic devices for medical and dental applications.

During the SLM process, the alloy powders are completely melted by a laser, and subsequently undergo rapid solidification. Therefore, this process can be used to produce objects of high geometrical complexity [3]. During fabrication, a high power laser beam is directed on an alloy bed and programmed to fuse particles according to a computer-assisted design (CAD) file [4]. This consequently generates a thin metal layer [4]. The apposition of subsequent layers results in the production of the desired three-dimensional (3D) form [4]. Therefore, using this technique, it is possible to fabricate medical and dental metallic devices of different shapes and sizes, directly from a CAD model [4].

However, the surface quality and mechanical properties of such SLM-fabricated metallic products may vary depending on the laser process parameters used [5-7]. Laser power, scan rate, and scan-line 
spacing, which directly affect the melting behavior of the metallic powders, are the common process parameters adjusted to optimize the process $[5,6,8]$. The laser beam melts the material along a specific line of powder particles, thereby forming a molten pool, which acquires the shape of a circular or segmental cylinder under the effect of surface tension [9]. The fragmentation of the remelted line is known as the balling effect, and is a well-known drawback of SLM $[5,9]$. The balling phenomenon renders it difficult to stack the subsequent layers, and occasionally causes failure during 3D printing. Therefore, the laser process parameters should be carefully controlled to successfully fabricate high-quality medical and dental metallic devices with appropriate surface roughness to eliminate post-processing procedures such as extensive finishing or polishing [10,11]. However, the relatively high surface roughness of SLM products is a significant drawback [10].

Recently, Pupo et al. [12] studied the influence of various process parameters on the surface quality of a $\mathrm{Co}-\mathrm{Cr}$ alloy produced by SLM. However, the results of the study were derived using a two-dimensional (2D) single-line formation test. Therefore, such evaluations should be extended to include multi-layer formation tests to determine how various processing parameters affect the surface roughness of 3D-printed $\mathrm{Co}-\mathrm{Cr}$ alloy products produced by SLM.

Therefore, the purpose of this laboratory study was to investigate the effect of three laser process parameters, namely laser power, scan rate, and scan-line spacing, on the surface roughness of an SLM-fabricated $\mathrm{Co}-\mathrm{Cr}$ alloy used for dental applications, using both single-line formation (2D) and multi-layer formation (3D) tests.

\section{Materials and Methods}

\subsection{Materials Used and Processing}

A commercially available Co-Cr dental alloy (Starbond Cos Powder, Scheftner GmbH, Mainz, Germany), with a composition of Co $56 \mathrm{wt} \%$, Cr $25 \mathrm{wt} \%$, tungsten $9.5 \mathrm{wt} \%$, and molybdenum $3.5 \mathrm{wt} \%$, was used. The average particle size of the alloy was less than $40 \mu \mathrm{m}$. AISI H13 tool steels (Orvar ${ }^{\circledR}$ Supreme, Uddeholm, Dublin, Ireland) were used as substrates.

An SLM machine (PNUME, Busan, Korea) was used for the tests; within the machine, an ytterbium fiber laser beam (IPG YL-200) with a spot size and maximum power of $0.08 \mathrm{~mm}$ and $200 \mathrm{~W}$, respectively, was operated under a nitrogen gas (flow rate $=5 \mathrm{~L} / \mathrm{min}$ ) atmosphere. During the SLM process, a Co-Cr powder layer was deposited onto the substrate. The laser beam scanned the powder bed and melted the powder. The melted metal immediately solidified, forming a 2D solid substrate region with a thickness of $50 \mu \mathrm{m}$ on top of the substrate (single-line formation). The stage was subsequently lowered, and the next layer of powder was deposited. Successive scans were performed, with the stage lowered each time, until the desired 3D structure was formed (multi-layer formation).

\subsection{Single-Line Formation Test}

To determine the optimal laser power and scan rate, a single-line formation test was performed, as shown in Figure 1. The $\mathrm{Co}-\mathrm{Cr}$ alloy powders were homogeneously applied onto the substrate using the powder application system; subsequently, each length $(7.0 \mathrm{~mm})$ of powder was selectively irradiated with the laser. The laser powers used were 100, 150, and $200 \mathrm{~W}$, and the scanning rate ranged from 3.66 to $300 \mathrm{~mm} / \mathrm{s}$. The energy density was calculated using the following equation [9]:

$$
\text { Energy density }(\mathrm{J} / \mathrm{mm})=P / v
$$

where $P$ is the laser power $(\mathrm{W})$, and $v$ is the scanning rate $(\mathrm{mm} / \mathrm{s})$. 


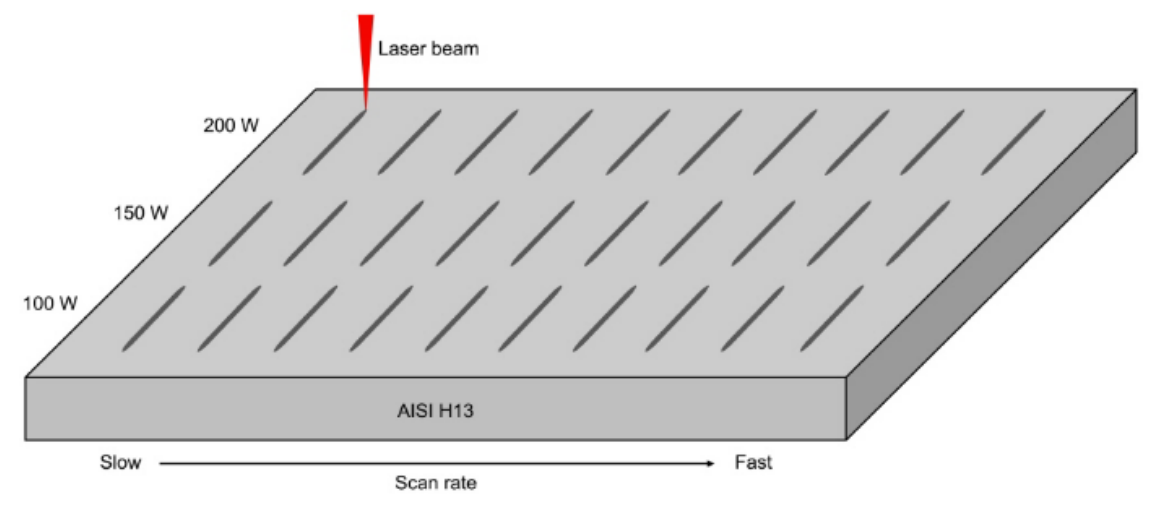

Figure 1. Schematic illustration of the single-line formation test.

To establish the optimal process parameters, an objective function $(F)$ was determined $[12,13]$. This considers the relationship between the melting zone area $\left(A_{1}\right)$ and the penetration zone $\left(A_{2}\right)$, as follows:

$$
F=A_{1} / A_{2}
$$

where

$$
A_{1}=\left(W_{1}+W_{3} / 2\right) \times H_{1}
$$

in which $H_{1}$ and $W_{1}$ are the height and width, respectively, of the upper part of the line. $W_{3}$ represents the length of the lower part of the trapezium that is circumscribed to the line. $A_{2}$ can be determined by

$$
A_{2}=H_{2} \times W_{2} / 2
$$

where $\mathrm{H}_{2}$ and $\mathrm{W}_{2}$ are the penetration zone areas, where remelting occurs. Finally, $F$ can be calculated using the following equation:

$$
F=\left[\left(W_{1}+W_{3}\right) \times H_{1}\right] / H_{2} \times W_{2}
$$

\subsection{Multi-Layer Formation Test}

To determine the optimal scan-line spacing, a multi-layer formation test (Figure 2) was performed. The powder layering was repeated 10 times to obtain a 3D object, using the optimal laser power and scan rate that had been determined using the single-line formation test. The scan-line spacing was set as 20,60,100,150, and $200 \mu \mathrm{m}$. The powder was deposited within an area measuring $5 \mathrm{~mm} \times 5 \mathrm{~mm}$. The powder layer thickness was $50 \mu \mathrm{m}$. Each layer was built with the laser scanning along a specific direction to reduce anisotropy [14]. Layer-by-layer the scanning direction was rotated by $90^{\circ}$ with respect to the previous one. The effect of the scan-line spacing on the shape of the deposited layer was determined using the overlap ratio, as follows [15]:

$$
\text { Overlap ratio }(\%)=(1-\text { scan-line spacing }(\mu \mathrm{m}) / \text { deposited width }(\mu \mathrm{m})) \times 100
$$

The surfaces were examined by scanning electron microscopy (SEM, JSM-6700F, Jeol, Tokyo, Japan). In addition, the 3D-surface profiles were obtained using phase-shift interferometry (Biolin Scientific Oy, Espoo, Finland). The average surface roughness, $R_{\mathrm{a}}$, was determined from the images. The Gaussian cutoff was $80 \mu \mathrm{m}$. The $R_{\mathrm{a}}$ of each specimen was recorded using the average value of five readings. 


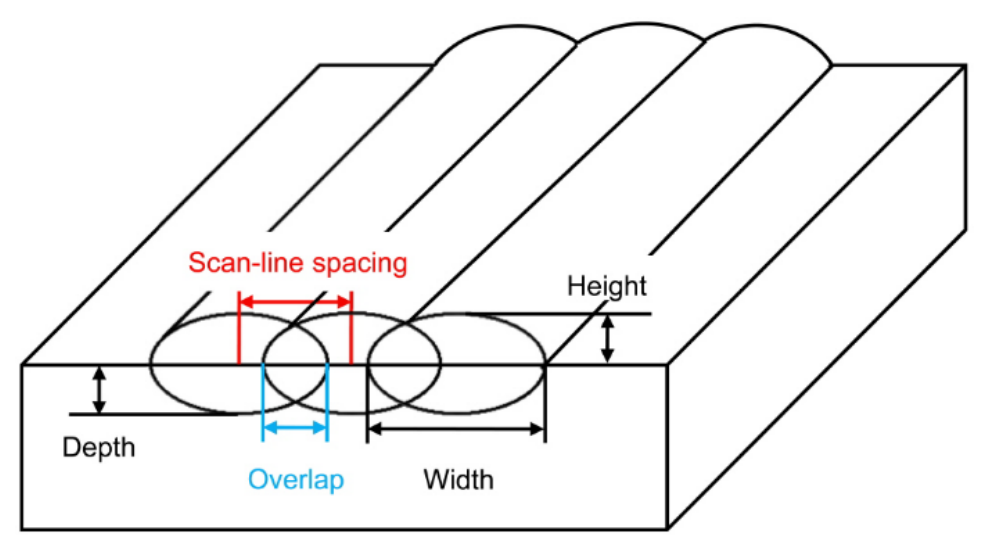

Figure 2. Schematic illustration of the multi-layer formation test.

\section{Results and Discussion}

\subsection{Single-Line Formation Test}

To fabricate defect-free SLM products, it is important to initially optimize the laser power and scan rate [16]. Figure 3 shows the results of the single-line formation test, which was performed to determine the two process parameters. Under all the applied laser powers and scan rates, three different line patterns could be observed, along with no melting [17]. The three different patterns can be described as follows: Single fused lines with significantly coarsened balling (type 1), single fused lines that are smooth and continuous (type 2), and single lines with a small amount of balling and/or discontinuous partial melting (type 3). These three different line patterns can be explained based on the energy density of the laser beam supplied to the metal powders [16].

The energy density describes the laser energy applied to the powders (Equation (1)). The range of energy densities is shown in Figure 4. When the energy density of the applied laser is sufficient to melt the powder, the melting zone enlarges, and the temperature in the vicinity of the melted zone remains high [17]. However, when the energy density of the applied laser is insufficient to fully melt the metal powder, unmelted powder remains on the layer, forming defects, because the temperature of the melting zone is insufficient.

In this study, perfect bonding between the powders and the substrate was achieved when the energy density was $1.4-5.1 \mathrm{~J} / \mathrm{mm}$ (type 2, Figure 3). Under this condition, it seems that a sufficient amount of liquid, with a reasonable stability, was formed; after solidification, this yielded continuous and smooth melted lines without the occurrence of balling. In contrast, when the energy density was lower than $1.3 \mathrm{~J} / \mathrm{mm}$, there was insufficient energy supplied to the powders, which caused poor adhesion between the powders and substrate (type 3, Figure 3). When the surface energy was reduced, the melt became highly instable; this resulted in the production of rough lines consisting of a number of small balls and/or partial melting on their surfaces.

However, the line formation was also compromised when the energy density was excessive (type 1, Figure 3) [13,17]. When the energy density was greater than $6.6 \mathrm{~J} / \mathrm{mm}$, a single fused line with significantly coarsened balling was observed (Figure 3). This balling phenomenon indicates that the melted powder grains stick together due to the surface tension force, forming a series of spheres, when the energy density is high $[16,17]$. Such high energy densities can be generally considered to be due to the high laser power and slow scan rate. 

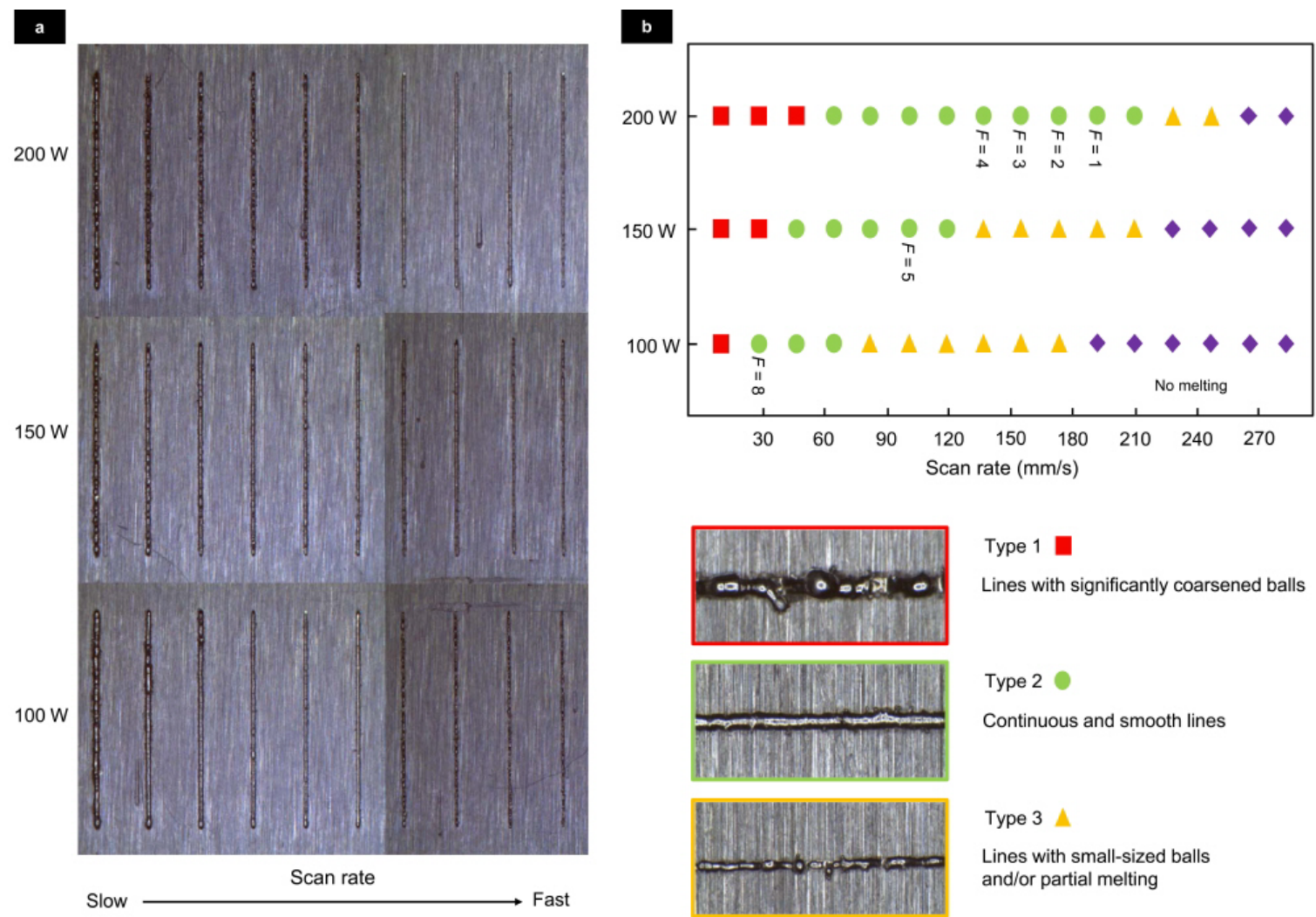

Type 1

Lines with significantly coarsened balls

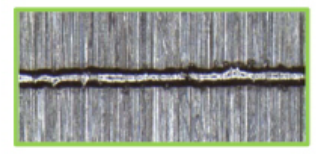

Type 2

Continuous and smooth lines

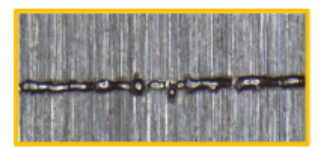

Type 3 A

Lines with small-sized balls and/or partial melting

Figure 3. Photograph (a) and map (b) showing the single-line formation test results. The beads obtained under six different conditions ( $F$ (objective function) $=1-5$, and 8 ), which resulted in the production of continuous and smooth lines (type 2), were further examined to determine the optimal process conditions (laser power and scan rate).

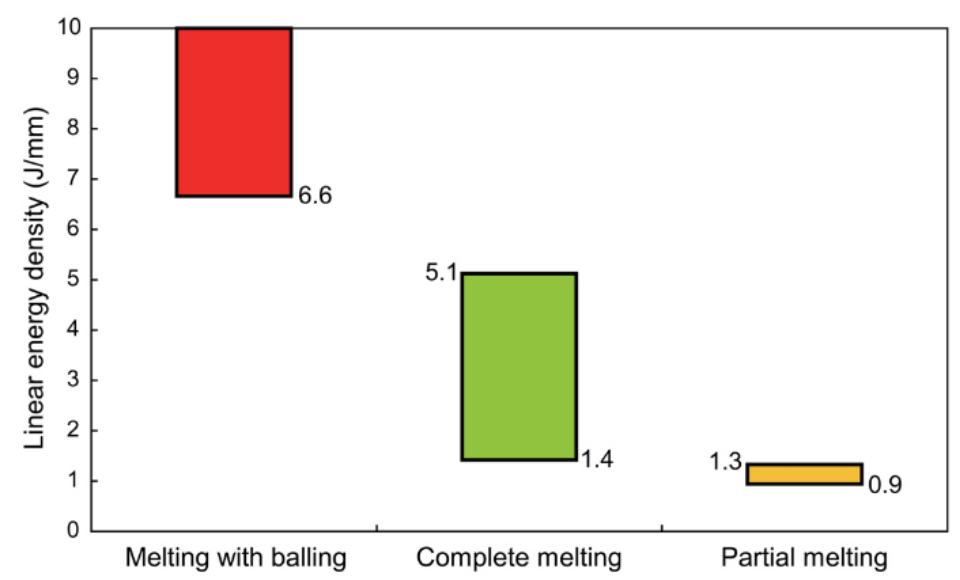

Figure 4. Energy density ranges under various laser powers and scan rates (see Figure 3).

In addition, as shown in Figure 5, the optimal laser power and scan rate were determined using the single-line formation test, based on the objective function, $F$ [12]. The beads produced on the substrate should form a stable line, where the melted zone and substrate are highly stable. Depending on the laser power and scan rate applied, $F$ values between 1 and 8 could be determined (Equations (1)-(5)). When the $F$ values increase, the average angle increases. The two angles $\left(\alpha_{1}\right.$ and $\alpha_{2}$, Figure 5$)$ indicate the line symmetry, which is a favorable characteristic for the overlapping of the lines. When $F=1-3$, the melting zone was unstable because of the shallow penetration depth (low $\mathrm{H}_{2}$ value), which was 
probably due to the overly high scanning rate. When the $F$ value increases, the $H_{1}$ value increases but the $\mathrm{H}_{2}$ value decreases. In a fixed laser power $(F=1-4)$, the width and depth of the melting zone were reduced at faster scan rates. This may have been due to the Marangoni convection in the melted pool $[18,19]$. The degree of convection is related to the total amount of energy supplied to the powder layer [20]. The flow of the molten metal is caused by local differences in the surface tension on the liquid surface, which is affected by the differences in temperature between different regions of the melt pool [19]. The final shape and size of the solidified bead is determined by those of the melting pool [19]. Therefore, a small bead is created when the scan rate is fast and the laser power is low. When the laser power was set as 100 and $150 \mathrm{~W}(F=5$ and 8$)$, the melting zone was unstable. When the laser power and scan rate were $200 \mathrm{~W}$ and $128.6 \mathrm{~mm} / \mathrm{s}$, respectively $(F=4)$, an optimal bead profile, with optimal height, depth, and width, was formed. According to Sing et al. [2], laser power and laser scan rate also affect the powder adhesion thickness. This was not investigated in this single-line formation test but would be worth further investigation.
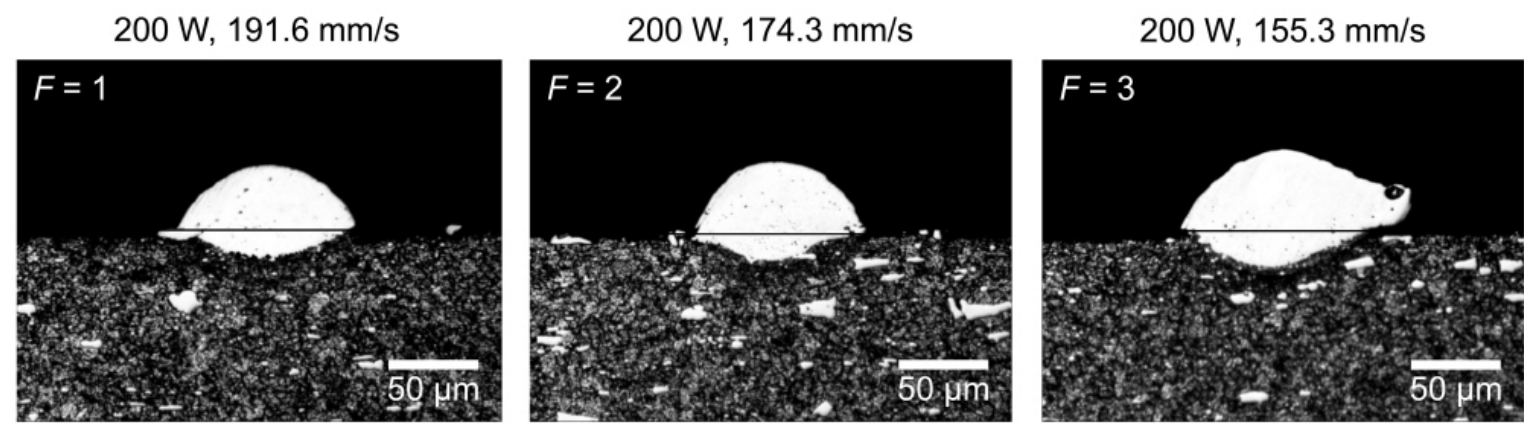

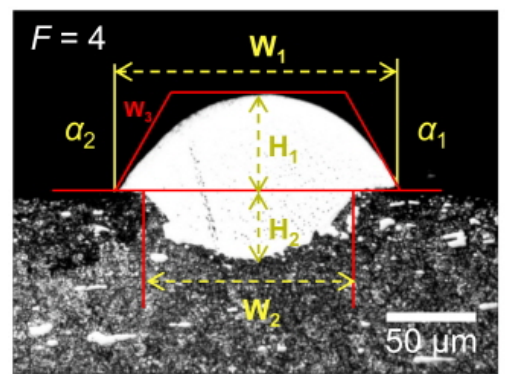

$200 \mathrm{~W}, 128.6 \mathrm{~mm} / \mathrm{s}$

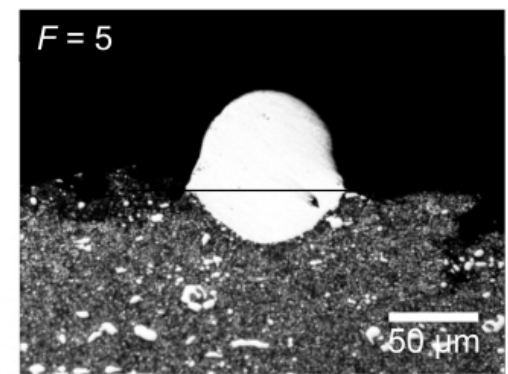

$150 \mathrm{~W}, 101.6 \mathrm{~mm} / \mathrm{s}$

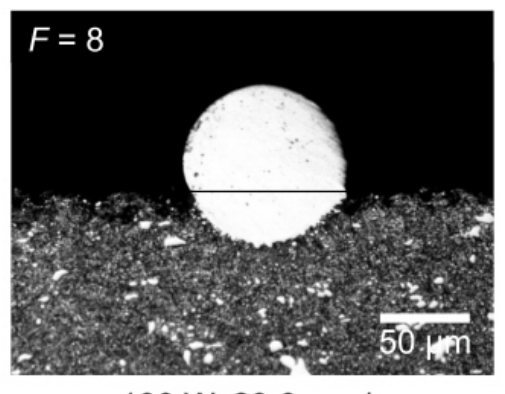

$100 \mathrm{~W}, 29.6 \mathrm{~mm} / \mathrm{s}$

Figure 5. Various bead shapes produced during the single-line formation test under six different conditions ( $F=1-5$, and 8) (see Figure 3). When the laser power and scan rate were $200 \mathrm{~W}$ and $128.6 \mathrm{~mm} / \mathrm{s}$, respectively ( $F=4$, see 2.2 to read the symbols), an optimal bead shape was achieved.

\subsection{Multi-Layer Formation Test}

As shown in Section 3.1, the optimal laser power and scan rate $(200 \mathrm{~W}$ and $128.6 \mathrm{~mm} / \mathrm{s}$, respectively) were determined through the single-line formation test (Figure 5). These values were used during the multi-layer formation test to fabricate 3D-printed $\mathrm{Co}-\mathrm{Cr}$ alloy products.

Figure 6 shows the surfaces of the 3D-printed bodies in accordance with the scan-line spacing used. In general, the overhang areas have a higher maximum temperature, a higher tensile stress, and a larger distortion than the areas above a solid substrate [21]. In addition, a higher energy density input (a lower scan rate or a higher beam current) may cause severe curling at the overhang area [21]. Prominent overhang area formation when the scan-line spacing values were 60 and $20 \mu \mathrm{m}$ indicates that a high energy density input was supplied to the bodies because of the high overlap ratios. 


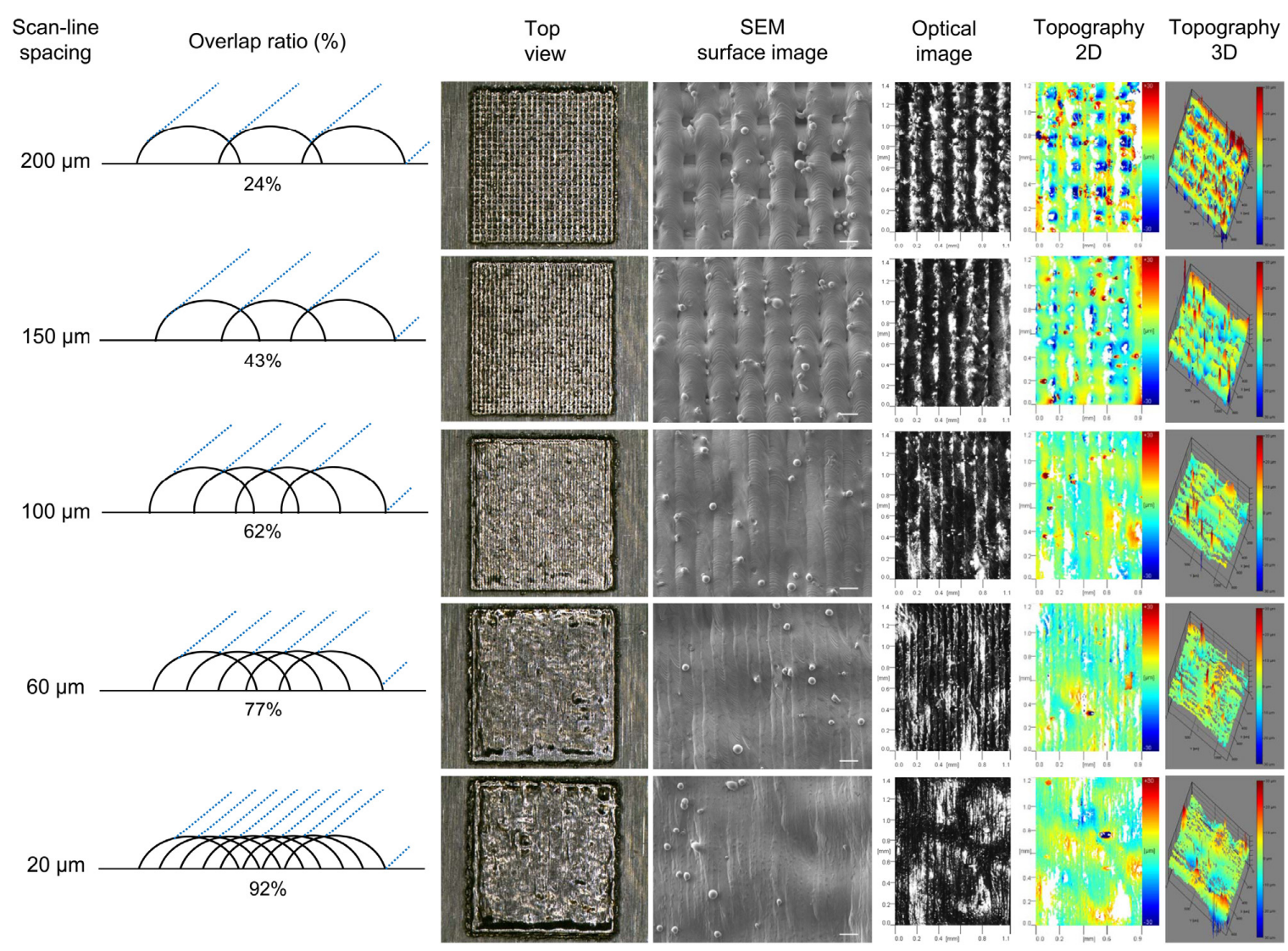

Figure 6. Photograph and map showing the multi-layer formation test results. The scanning electron microscopy $($ SEM) surface images are also shown $(100 \times$, scale bar $=100 \mu \mathrm{m})$. The optical and topography (2D and 3D) images are obtained from the phase-shift interferometry. Optimal melting was achieved when the scan-line spacing was $100 \mu \mathrm{m}$.

As also shown in Figure 6, the overlap ratio tends to decrease as the scan-line spacing increases (Equation (6)) [22]. Considering the various scan-line spacing values used, the surface shape of the melted powder was classified into three different groups according to the overlap ratio, as follows [12]: (1) a clear mesh-structured surface at small overlap ratios ( $24 \%$ and $43 \%)$; (2) a flat and smooth surface by optimal overlapping (62\%); and (3) excessive overlapping of the lines of the melted material (77\% and $92 \%$ ) with occurrence of swelling [23]. When the overlap ratios were $24 \%$ and $43 \%$, the SEM image showed rough surfaces with many small melt balls [23]. In contrast, when the overlap ratios were excessively high (77\% and $92 \%)$, swelling, which is the rise of solid material above the plane of powder distribution and melting, was prominent on the SEM surface images [23]. When the overlap ratio was $62 \%$, the SEM image revealed uniform-shaped lines. Although a slight melt ball formation was also detected on the surface, this does not seem to have an obvious detriment to SLM quality [24]. In the present multi-layer formation test, therefore, the most stable deposition was achieved when the scan-line spacing was $100 \mu \mathrm{m}$; as a result, the overlap ratio was $62 \%$.

Figure 7 shows the $R_{\mathrm{a}}$ values according to the scan-line spacing values and overlap ratios. When the scan-line spacing was 200 and $150 \mu \mathrm{m}$, the surfaces were uneven and had higher $R_{\mathrm{a}}$ values (6.2 and $4.1 \mu \mathrm{m}$, respectively); this was probably due to small overlap ratios and the occurrence of the non-connected line formation (Figure 6). When scan-line spacing values of 60 and $20 \mu \mathrm{m}$ were used, the 3D-printed bodies had rough surfaces $\left(R_{\mathrm{a}}=3.3\right.$ and $3.9 \mu \mathrm{m}$, respectively); this was probably due to the excessive melting, swelling, and excessive overlap ratios. The smoothest surface $\left(R_{\mathrm{a}}=1.8 \mu \mathrm{m}\right)$ was obtained when the scan-line spacing was $100 \mu \mathrm{m}$ (overlap ratio $=62 \%$ ). These findings suggest that 
use of the optimal scan-line spacing results in an overlap ratio that is slightly more than $50 \%$, which enhances the surface quality of the 3D-printed Co-Cr alloy products.

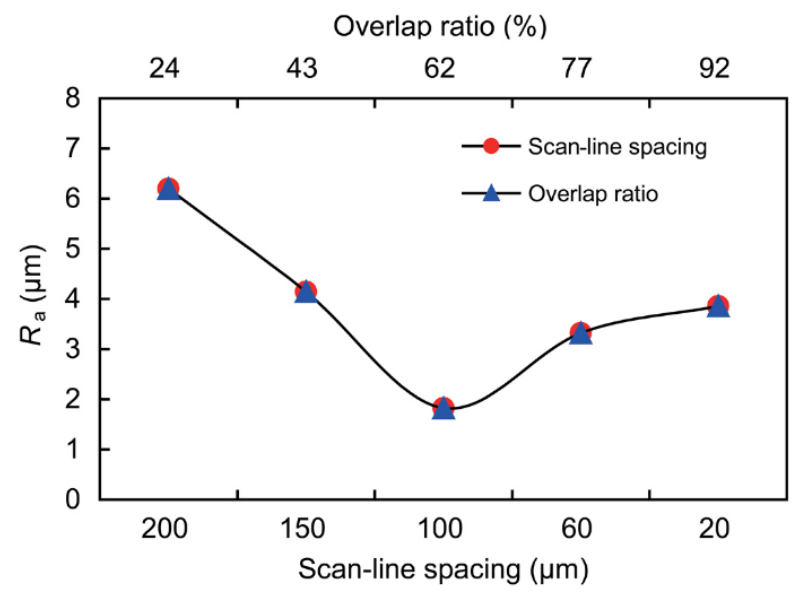

Figure 7. $R_{\mathrm{a}}$ as a function of the scan-line spacing and overlap ratio.

It should be noted that the results of the multi-layer formation test (Figures 6 and 7) were derived from the simplified experimental design (in particular, the number of deposited layers). Therefore, investigations involving simulations that are closer to the actual cases in dentistry are required to determine the effect of laser process parameters on the surface quality of the SLM-fabricated Co-Cr dental alloys. Recently, Kruth et al. [11,25] suggested that surface remelting is a simple and effective method for bringing about a significant improvement in the surface roughness of SLM products. This technique may also be applicable to $\mathrm{Co}-\mathrm{Cr}$ dental alloys produced by SLM, and this possibility needs to be investigated. The careful selection of processing parameters is also important to minimize pore formation and to improve the mechanical properties of an SLM object $[6,8,26,27]$. This is beyond the scope of this study but would be a valuable next step to validate our findings on a larger scale.

\section{Conclusions}

By reducing the laser power and increasing the scan rate during a single-line formation test, melting with balling was avoided. The alloys did not melt completely unless the laser output and scan rate were set at specific levels. In the case of the multi-layer formation test, the smoothest surface was achieved when a scan-line spacing of $100 \mu \mathrm{m}$ was used. It was confirmed that the laser power, scan rate, and scan-line spacing are key factors for determining the surface quality of $\mathrm{Co}-\mathrm{Cr}$ dental alloys produced by SLM. The production of 3D-printed metallic products with smooth surfaces would help to minimize the amount of post-processing required, such as finishing and polishing.

Acknowledgments: This work was supported by the National Research Foundation of Korea (NRF) grant funded by the Korea government (MSIP) (2008-0062282).

Author Contributions: Min-Ho Hong and Tae-Yub Kwon conceived and designed the experiments; Min-Ho Hong performed the experiments; Bong Ki Min and Tae-Yub Kwon analyzed the data; Min-Ho Hong and Tae-Yub Kwon wrote the paper.

Conflicts of Interest: The authors declare no conflict of interest. The founding sponsors had no role in the design of the study; in the collection, analyses, or interpretation of data; in the writing of the manuscript; or in the decision to publish the results.

\section{References}

1. Kruth, J.P.; Froyen, L.; Van Vaerenbergh, J.; Mercelis, P.; Rombouts, M.; Lauwers, B. Selective laser melting of iron-based powder. J. Mater. Process. Technol. 2004, 149, 616-622. [CrossRef] 
2. Sing, S.L.; Yeong, W.Y.; Wiria, F.E.; Tay, B.Y. Characterization of titanium lattice structures fabricated by selective laser melting using an adapted compressive test method. Exp. Mech. 2016, 56, 735-748. [CrossRef]

3. Das, S.; Wohlert, M.; Beaman, J.J.; Bourell, D.L. Processing of titanium net shapes by SLS/HIP. Mater. Des. 1999, 20, 115-121. [CrossRef]

4. Figliuzzi, M.; Mangano, F.; Mangano, C. A novel root analogue dental implant using CT scan and CAD/CAM: Selective laser melting technology. Int. J. Oral Maxillofac. Surg. 2012, 41, 858-862. [CrossRef] [PubMed]

5. Yadroitsev, I.; Smurov, I. Surface morphology in selective laser melting of metal powders. Phys. Procedia 2011, 12, 264-270. [CrossRef]

6. Yap, C.Y.; Chua, C.K.; Dong, Z.L.; Liu, Z.H.; Zhang, D.Q.; Loh, L.E.; Sing, S.L. Review of selective laser melting: Materials and applications. Appl. Phys. Rev. 2015, 2, 041101. [CrossRef]

7. Do, D.K.; Li, P. The effect of laser energy input on the microstructure, physical and mechanical properties of Ti-6Al-4V alloys by selective laser melting. Virtual. Phys. Prototyp. 2016, 11, 41-47. [CrossRef]

8. Sing, S.L.; An, J.; Yeong, W.Y.; Wiria, F.E. Laser and electron-beam powder-bed additive manufacturing of metallic implants: A review on processes, materials and designs. J. Orthop. Res. 2016, 34, 369-385. [CrossRef] [PubMed]

9. Yadroitsev, I.; Gusarov, A.; Yadroitsava, I.; Smurov, I. Single track formation in selective laser melting of metal powders. J. Mater. Process. Technol. 2010, 210, 1624-1631. [CrossRef]

10. Vandenbroucke, B.; Kruth, J.P. Selective laser melting of biocompatible metals for rapid manufacturing of medical parts. Rapid Prototyp. J. 2007, 13, 196-203. [CrossRef]

11. Kruth, J.P.; Badrossamay, M.; Yasa, E.; Deckers, J.; Thijs, L.; Van Humbeeck, J. Part and Material Properties in Selective Laser Melting of Metals. In Proceedings of the 16th International Symposium on Electromachining, Shanghai, China, 19-23 April 2010.

12. Pupo, Y.; Monroy, K.P.; Ciurana, J. Influence of process parameters on surface quality of CoCrMo produced by selective laser melting. Int. J. Adv. Manuf. Technol. 2015, 80, 985-995. [CrossRef]

13. Ciurana, J.; Hernandez, L.; Delgado, J. Energy density analysis on single tracks formed by selective laser melting with CoCrMo powder material. Int. J. Adv. Manuf. Technol. 2013, 68, 1103-1110. [CrossRef]

14. Barucca, G.; Santecchia, E.; Majni, G.; Girardin, E.; Bassoli, E.; Denti, L.; Gatto, A.; Iulianod, L.; Moskalewicz, T.; Mengucci, P. Structural characterization of biomedical Co-Cr-Mo components produced by direct metal laser sintering. Mater. Sci. Eng. C 2015, 48, 263-269. [CrossRef] [PubMed]

15. Jang, J.H.; Joo, B.D.; Van Tyne, C.J.; Moon, Y.H. Characterization of deposited layer fabricated by direct laser melting process. Met. Mater. Int. 2013, 19, 497-506. [CrossRef]

16. Jang, J.H.; Mun, S.M.; Kim, T.H.; Moon, Y.H. Process analysis of direct laser melting to fabricate layered hybrid beads. Trans. Nonferr. Met. Soc. China 2012, 22, s813-s819. [CrossRef]

17. Gu, D.; Shen, Y. Balling phenomena in direct laser sintering of stainless steel powder: Metallurgical mechanisms and control methods. Mater. Des. 2009, 30, 2903-2910. [CrossRef]

18. Bauer, H.F.; Buchholz, A. Marangoni convection in a rectangular container. Forsch. Ing. 1998, 63, 339-348. [CrossRef]

19. Louvis, E.; Fox, P.; Sutcliffe, C.J. Selective laser melting of aluminium components. J. Mater. Process. Technol. 2011, 211, 275-284. [CrossRef]

20. Khan, M.; Dickens, P. Selective laser melting (SLM) of gold (Au). Rapid Prototyp. J. 2012, 18, 81-94. [CrossRef]

21. Cheng, B.; Chou, K. Thermal Stresses Associated with Part Overhang Geometry in Electron Beam Additive Manufacturing: Process Parameter Effects. In Proceedings of the 25th Annual International Solid Freeform Fabrication Symposium, Austin, TX, USA, 4-6 August 2014.

22. Qin, Q.; Chen, G.X. Effects of parameters on surface roughness of metal parts by selective laser melting. Adv. Mater. Res. 2014, 834-836, 872-875. [CrossRef]

23. Sames, W.J.; List, F.A.; Pannala, S.; Dehoff, R.R.; Babu, S.S. The metallurgy and processing science of metal additive manufacturing. Int. Mater. Rev. 2016, 61, 315-360. [CrossRef]

24. Li, R.; Liu, J.; Shi, Y.; Wang, L.; Jiang, W. Balling behavior of stainless steel and nickel powder during selective laser melting process. Int. J. Adv. Manuf. Technol. 2012, 59, 1025-1035. [CrossRef]

25. Kruth, J.P.; Levy, G.; Klocke, F.; Childs, T.H.C. Consolidation phenomena in laser and powder-bed based layered manufacturing. CIRP Ann. Manuf. Technol. 2007, 56, 730-759. [CrossRef] 
26. Ang, K.C.; Leong, K.F.; Chua, C.K.; Chandrasekaran, M. Investigation of the mechanical properties and porosity relationships in fused deposition modelling-fabricated porous structures. Rapid Prototyp. J. 2006, 12, 100-105.

27. Yang, Y.Q.; Lu, J.B.; Luo, Z.Y.; Wang, D. Accuracy and density optimization in directly fabricating customized orthodontic production by selective laser melting. Rapid Prototyp. J. 2012, 18, 482-489. [CrossRef]

(C) 2016 by the authors; licensee MDPI, Basel, Switzerland. This article is an open access article distributed under the terms and conditions of the Creative Commons Attribution (CC-BY) license (http:/ / creativecommons.org/licenses/by/4.0/). 